\title{
Translational research of natriuretic peptide family Kazuwa Nakao*
}

Address: Division of Endocrinology and Metabolism, Department of Medicine and Clinical Science, Kyoto University Graduate School of Medicine, Sakyoku, Kyoto, Japan

Email: Kazuwa Nakao* - nakao@kuhp.kyoto-u.ac.jp

* Corresponding author

from $3^{\text {rd }}$ International Conference on cGMP Generators, Effectors and Therapeutic Implications

Dresden, Germany. I5-17 June 2007

Published: 25 July 2007

BMC Pharmacology 2007, 7(Suppl I):S32 doi:10.1 I86/I47|-22I0-7-SI-S32

This abstract is available from: http://www.biomedcentral.com/I47I-22I0/7/SI/S32

(c) 2007 Nakao; licensee BioMed Central Ltd.

The natriuretic peptide family is the prototype of cardiovascular hormones. The natriuretic peptide family consists of atrial natriuretic peptide (ANP), brain natriuretic peptide (BNP), and C-type natriuretic peptide (CNP). ANP and BNP exert their biological actions via a particulate guanylyl cyclase A (GC-A), whereas CNP activates the other guanylyl cyclase B (GC-B). ANP is a cardiac hormone produced by the atrium. BNP first isolated from the brain is now known to be a cardiac hormone produced by the ventricle of the heart. CNP is the main natriuretic peptide in the central nervous system and is also produced by vascular endothelial cells, macrophages, and chondrocytes, indicating that CNP is a local regulator rather than a circulating hormone. Clinical application of ANP as a therapeutic drug for patients with congestive heart failure started from 1995 in Japan. Measurement of plasma ANP and BNP concentrations as diagnostic tools are also widely used. In order to further promote the clinical application and elucidate the physiological implication of the natriuretic peptide system, we have developed transgenic and knockout mice of the natriuretic peptide family. Recently, we demonstrated that CNP is a very strong stimulator of endochondral bone growth [1,2]. CNP knockout mice are dwarf with impaired bone growth. CNP transgenic mice with overexpressed CNP in cartilage are elongated with skeletal overgrowth. Therefore, we have tried to rescue mice model of achondroplasia, the most common genetic form of human dwarfism with an activated FGF receptor 3 by CNP and successfully demonstrated that targeted overexpression of CNP in cartilage counteracts their dwarfism. CNP prevented the shortening of achondro- plastic bones by correcting the decreased extracellular matrix synthesis in the growth plate through inhibition of the MAPK pathway of FGF signalling $[3,4]$. These results indicate that activation of CNP/GC-B system in endochondral bone formation constitutes a novel therapeutic strategy for skeletal dysplasias including achondroplasia, of which there was no efficient medical treatment. We are now undergoing translational research of CNP/GC-B system on achondroplasia and other skeletal dysplasias.

\section{References}

I. Suda M, Ogawa Y, Tanaka K, Tamura N, Yasoda A, Takigawa T, Uehira M, Nishimoto H, Itoh H, Saito Y, Shiota K, Nakao K: Skeletal overgrowth in transgenic mice that overexpress brain natriuretic peptide. Proc Natl Acad Sci 1998, 95:2337-2342.

2. Yasoda A, Ogawa Y, Suda M, Tamura N, Mori K, Sakuma Y, Chusho $\mathrm{H}$, Shiota K, Tanaka K, Nakao K: Natriuretic peptide regulation of endochondral ossification. Evidence for possible roles of the C-type natriuretic peptide/guanylyl cyclase-B pathway. J Biol Chem 1998, 273: I I695-II 700.

3. Chusho H, Tamura N, Ogawa Y, Yasoda A, Suda M, Miyazawa T, Nakamura K, Nakao K, Kurihara T, Komatsu Y, Itoh H, Tanaka K, Saito $Y$, Katsuki M, Nakao K: Dwarfism and early death in mice lacking C-type natriuretic peptide. Proc Natl Acad Sci 200I, 98:4016-4021.

4. Yasoda A, Komatsu Y, Chusho H, Miyazawa T, Ozasa A, Miura M, Kurihara T, Rogi T, Tanaka S, Suda M, Tamura N, Ogawa Y, Nakao K: Overexpression of CNP in chondrocytes rescues achondroplasia through a MAPK-dependent pathway. Nat Med 2004, 10:80-86. 